\title{
Design and Intervention in the Age of "No Alternative"
}

\author{
SILVIA LINDTNER, University of Michigan, USA \\ SHAOWEN BARDZELL, Indiana University, USA \\ JEFFREY BARDZELL, Indiana University. USA
}

\begin{abstract}
This paper explores the relationship between design and intervention, and how scholars of computing and design might strengthen their repertoire of intervention amidst a pervasive sense of there being "no alternative" to structures of inequality and capitalist expansion. Drawing from the authors' long-term ethnographic research on maker, entrepreneurship, and innovation cultures as well as their engagements with professional communities of computing and design, this paper introduces and theorizes modes of intervention that do not fit familiar images of political action such as the countercultural hero or localized resistance. The paper contributes by expanding the analytical repertoire of an interventionist-oriented social computing scholarship. Specifically, it offers three inter-related analytical sensibilities from feminist and critical race studies-"noticing differently," "walking alongside" and "parasitic resistance"- to support political and activist approaches in CSCW and related fields ${ }^{1}$.
\end{abstract}

\section{KEYWORDS}

Intervention, alternative, China, Taiwan, political economy, capitalism, design, maker, feminist, race.

\section{ACM Reference format:}

Silvia Lindtner, Shaowen Bardzell, and Silvia Lindtner. 2018. Design and Intervention in the Age of "No Alternative." In Proceedings of the ACM on Human-Computer Interaction, Vol. 2, CSCW, Article 109 (November 2018). ACM, New York, NY. 21 pages. https://doi.org/10.1145/3274378

\section{INTRODUCTION}

Technology researchers with an interest in politics, social justice, and activism work within a conflicted space. On the one hand, a range of computing fields from computer science to more interdisciplinary approaches in information studies, CSCW (computer supported cooperative work) and HCI (human computer interaction) have historically downplayed the role of overtly critical and political approaches for the advancement of their fields [[6], [14]]. On the other hand, computing scholarship has opened up and diversified over the past ten years. Researchers have begun to consider not only design but also policy implications [[54]], account for colonial legacies in computing and design [[17], [34], [51],] acknowledge the complicity with market economies [[67], [75]] as well as ongoing exclusions along the lines of gender, race, and class [[28], [35], [43], [66], [86]]. And several strands of research have embraced openly political stances including but not

This work is supported by the NSF, under grants \#1617898, \#1513596, \#1516204, \#1513604

Author's addresses: Silvia Lindtner, University of Michigan, School of Information, 105 S. State Street, Ann Arbor, MI-48109, USA; Shaowen Bardzell, Indiana University, Informatics West 207, Bloomington, IN, USA; Jeffrey Bardzell, Indiana University, Informatics West 203, Bloomington, IN, USA.

Permission to make digital or hard copies of all or part of this work for personal or classroom use is granted without fee provided that copies are not made or distributed for profit or commercial advantage and that copies bear this notice and the full citation on the first page. Copyrights for components of this work owned by others than ACM must be honored. Abstracting with credit is permitted. To copy otherwise, or republish, to post on servers or to redistribute to lists, requires prior specific permission and/or a fee. Request permissions from Permissions@acm.org. Copyright (C) ACM 2018 2573-0142/2018/November - Article $109 \$ 15.00$ https://doi.org/10.1145/3274378 
limited to adversarial design [[33]], critical design [[34]], feminist [[11], [13], [14], [42], [43], [85], [86]] and postcolonial computing [[17], [34], [51]], HCID [[93]], and interventions in digital labor exploitation [[52]].

Despite these shifts, it can be difficult to legitimize political work and commitments to intervention and activism as a central, rather than peripheral, part of computing scholarship, design practice and research. Politically oriented research has faced challenges gaining recognition, as seen in the legitimation challenges that action researchers have long chronicled [[50]]. Funding agencies such as the U.S. National Science Foundation tend to shy away from politically oriented work. And scholars of computing, STS (science and technology studies), and critical theory alike have argued that critical studies have failed in their purpose to bring about political change [[10], [37], [61]]. Perhaps this is because the grip of the neoliberal and capitalist market economy seems so tight that "there is no alternative," as Margaret Thatcher so famously put it in the 1980s, or, as Slavoj Žižek said at an Occupy rally, "It's easy to imagine the end of the world-an asteroid destroying all of life, and so on-but we cannot imagine the end of capitalism."

The goal of this paper, then, is to continue a line of work that has been developing analytical and methodological repertoires for an interventionist-oriented computing scholarship. It is motivated by the recognition that what counts as democratic, social justice, intervention, and participation are often so specific and pre-defined that a variety of interventions go unnoticed even when they unfold right in front of us. Part of the challenge, as suggested by feminist political theorists Seyla Benhabib [[16]] and Ruth Levitas [[64]], is that expectations can be so high-we call for "real democracy" and "real participation" and "real emancipation"- that we dismiss other forms of interventions that are effective yet problematic, worthwhile yet shy of utopian. Another challenge is the tendency to expect interventions to follow already familiar narratives (often romanticized), for instance that of the countercultural hero who fights the dominant power and wins, from Erin Brockovich to Steve Jobs.

In our long-term ethnographic research with design, maker, and engineering cultures, we have encountered modes of intervention with and through technology that are neither utopian nor heroic. In the age of no alternative, intervention can and indeed already does happen, and it can be politically effective despite its limitations and confounds. Learning from such stories requires a practice of-what feminist anthropologist Anna Tsing calls—noticing differently [[94]]. Noticing differently means to acknowledge and simultaneously step out of familiar frames of reference.

For instance, we have for years researched design and innovation practices in China and Taiwan. It has been difficult to articulate our observations without falling back into Western narratives of the exotic other: that they are copycats, that they are collectivists vs. individualists, that they follow behind and learn from the West, that in some ways they are still developing or are threatening Western democracy or leadership. At times, it was difficult for us to have such observations in the first place. Technology-relevant interventions in China and Taiwan are intertwined in contemporary projects of nation building as well as with complex historical processes of Western colonialization and modernization-fundamental to but often treated as unspoken backdrops to such projects. To come from Western academic environments to investigate cultures of innovation in China and Taiwan - even when each of us speaks Mandarin, all have lived in China or Taiwan, and one grew up in Taiwan - often entails unconsciously grafting Western IT narratives onto cultural situations that are not Western. Yet, complicatedly, actors in those situations themselves often have lived in and seek to emulate Silicon Valley-and so our own biases become entangled with their aspirations. 
This paper contributes to politically oriented computing scholarship and CSCW's research repertoire concerning the relations between IT innovation and political intervention, particularly as they occur in seemingly unchangeable and inevitable structures, such as capitalism, authoritarian rule, and entrenched political conflict. This contribution might not yield canonical design research contributions, such as a system or implications for design [[29]]. Its style of inquiry and written outcomes might not cohere with canonical scientific processes and outcomes: we do not, for example, structure this paper using the IMRaD format (Introduction, Methods, Results, and Discussion). It might offer, instead, alternative ways of noticing and seeing the world around us [[27]], draw out implications for policy [[54], [67]] and tinker with concrete alternatives [[42], [68], [86]] - each of these, we believe, contributes to a developing repertoire for politically oriented computing research.

With this approach, we are particularly indebted to and build on a long line of feminist scholarship by women of color who have informed our own thinking as well as many of the works we cite; Seyla Benhabib, Nancy Chen, Wendy Chun, Lisa Nakamura, Aiwah Ong, and Anna Tsing [[16], [24], [25], [75], [78], [94]]. Inspired by their work, we argue for the importance of noticing interventions within the gaps, cracks and fissures of neoliberal capitalism [[16], [95]] rather than in some idealized outside to create openings for social justice and other modes of solidarity. Using a combination of stories from our multi-sited ethnography and feminist sensibilities, we seek to understand people intervening in contexts of international and global orders that are extremely difficult to influence, including contemporary neoliberal capitalism and the fraught status quo between China and Taiwan. We will argue for and show that intervention is possible, meaningful, and impactful. But we will also argue that this intervention is difficult to notice without expanding how social computing is pursued as a scholarly project.

\section{DESIGN AS INTERVENTION, BEING ALONGSIDE, PARASITES}

This paper begins from the understanding that design is always already political. Design is intervention. It changes experiences, situations, practices, and beyond. It also participates in - at times alleviating, at times exacerbating - issues of national and even global importance, including economic development, social justice, and environmental impact. In interdisciplinary fields like CSCW, social computing, and HCI, the democratization of technology design and production is a long-running agenda [[9]]. This agenda manifests itself in Alan Cooper's [[27]] attempts to prevent a "digital apartheid" between workers who could and could not use computers, Scandinavian participatory design [[19], [39], [58]], Batya Friedman's values-sensitive design [[44]], research seeking to empower end users [[22]], the maker movement [[69]], ICTD [[93]], Manzini's [[73]] and Papanek's [[80]] respective notions of social design, among others.

Celebrating this potential of design, STS scholar Bruno Latour [[62]] argued that "design has replaced the word revolution." He explains, "to say that something has to be designed or redesigned (including nature), we imply something of the sort: 'it will neither be revolutionized, nor will it be modernized'." Latour, here, argues that design has taken on the social role performed in the past for political activists, reformers, politicians, and - of course - scientists; i.e. intervene on existing structures and conditions. But in contrast to revolutionaries, design does not overthrow the system, according to Latour; instead, it re-makes the world based on a stance that entails humility, craftsmanship, attention to material details, a sensitivity for meaning, a propensity to re-design rather than starting from scratch, and finally a moral responsibility or accountability. Design emerged and gained force, Latour argues, at a moment when it became impossible to sustain a 
subjectivity $^{2}$ of the removed (scientific) observer who "is just stating what is." As we redesign cities, landscapes, natural parks, societies, as well as genes, brains and chips, no designer can hide behind the old protection of matters of fact. Design made it impossible, in other words, to deny responsibility, authorship, and complicity.

If Latour was right, design is political through and through. Indeed, interactive and collaborative technologies have seen unprecedented growth and power in their global distribution and impact - from social media platforms to the Internet of Things, and from Big Data to selfdriving cars. Many of the largest and most influential multinationals today are IT-based: Apple, Google, Microsoft, Facebook, Tencent, Alibaba. The old promise that technology was neutral has become increasingly hard to sustain as mass surveillance creates ever more powerful states and industrial giants; security vulnerabilities give state-sponsored and criminal hackers alike tremendous power over our lives; disinformation campaigns designed to sway elections; and ever more sophisticated forms of automation that seem to proliferate precarious work conditions across different sectors of the population [[45], [52], [81], [84]].

This notion of design and tech production as inherently political is, however, all but pervasive in the very fields of technology design and computing. This is despite the fact that design has become a central instigator in social, economic, and political transformations - from design thinking and user experience design to notions of design as science, [[4], [5]]. It is deployed by managers to retrain their workforce as creative problem solvers and by governments and policy makers to cultivate citizens as entrepreneurial citizens who address challenges in health, environment catastrophes, and the future of work [[21], [23], [53]]. In other words, as Lucy Kimbell elucidates, design converts problems into opportunities for economic and social development [[55]]. It is exactly this complicity with a political economy of opportunity, optimism, and value creation that assigns responsibility to individuals that has made it much harder to sustain the myth of the designer/engineer/technologist as a countercultural renegade.

The question of complicity is a central theme in renewed critiques of capitalism that often focus centrally on the role of digital technology and computing. It features in what Boltanksi and Chiapello (2007) call "the new spirit of capitalism," i.e., capitalism feeding on the critiques and social movements leveled against it. In their view, capitalism works because it absorbs part of its critique. Their specific focus was on how the values the 1968 political revolts in Europe, such as freedom, autonomy, creativity, openness and mobility, were assimilated into libertarian ways of profit making. This argument has found much resonance amongst technology researchers interested in social justice and political intervention. Christian Fuchs, for instance, argues that Google "is a prototypical implementation" of "the new spirit of capitalism" in that its form of "coercion is ideological and social, built into the company's culture of fun, playbour (play labor), employee service, and peer pressure" [Fuchs, p. 228]. Söderberg and Delfanti, in a similar vein, draw from Boltanski and Chiapello to urge that a study of hacking - no matter if on the scale of social movements or individual subjectivities - must weigh promises for emancipatory potential "against the likelihood of a future recuperation of the same practices" [[87], p. 794]. "Technological innovations by hackers," they argue, "constitute the material infrastructure of today's capitalism" [[87], p. 796].

\footnotetext{
${ }^{2}$ By subjectivity and subject position, we refer to the following: a subject position refers to "the social roles that people are thrust into" while a subjectivity is "the felt experience and creative agency of individuals within that situation" [[8]]. This paper begins from an understanding that design constructs, i.e. cultivates, shapes and/or limits, both people's subjectivity and subject position [[8], [48]].
} 
Studying such processes of economization is crucial to move beyond naïve renderings of technology research and design as "neutral," "apolitical" or outside past and continuous economic and political processes. Such critiques are often met, however, with a level of suspicion by technologists and technology researchers. A common response we have encountered, for instance, has been that such critiques are "negative" and that a focus on politics or political economy would deter us from solvable problems at hand.

In what follows, we show how a feminist sensibility can offer a way to proceed with an interventionist computing agenda that neither falls back onto stories of technological promise nor shuts down alternatives via stories of inevitability. For the purposes of this paper, we draw specifically on Joanna Latimer's "walking alongside" and Anna Fisher's "parasitic resistance." Both approaches, we argue, can further an interventionist-oriented computing scholarship to notice and then to build on subjectivities and practices that are politically efficacious despite their partial complicity with capitalist structures. Latimer's walking alongside suggests a relationship of two actors or group of actors who maintain their separation, and in fact cannot comprehend each other, but who at times cooperate because it is within their own interests to do so. This type of subjectivity foregrounds new types of encounter and unexpected conviviality via an affective relation that cannot be put into a shared vocabulary, because there is no such vocabulary. "Being alongside" [[60]] can be thought of similar to the ways in which animals in the city cohabit with humans, without necessary sharing mutual understanding or purpose.

In an adjacent move, what Anna Fisher calls parasitic resistance refers to entity that is dependent on a host yet pursues independent goals, including goals that go against the interests of the host [[96]]: "The parasite-host system thus offers a temporal (enduring), spatial (immanent), and relational (dependent) model wherein embeddedness and relative contingency do not mean total subsumption or eventual assimilation but signal the possibility of incrementally redirecting the host's resources from inside. In an inevasible contemporary social, political, and economic system, parasites demonstrate that enmeshment need not be antithetical to disruptive action." With the notion of "parasitic resistance," Fisher deconstructs tendencies to couple autonomy and agency and offers an alternative language to the imagery of the countercultural hero or binaries such as "the system" vs "the resistance."

In what follows, we employ these two analytical sensibilities in order to notice intervention as it unfolds in the gaps and fissures of contemporary capitalism [[16], [95]]. We will show subjectivities of intervention other than the romantic genius and the countercultural hacker, i.e. the way we often link success stories to individuals [[81]]. This tendency to view technological promise as embodied in a charismatic figure is fueled in part by older visions of the technological hacker and rebel, the 1960s countercultural hero. Thus we often hear the story of how Steve Jobs began as a hacker in his garage, founded a company that stood up to Microsoft, and later gave us the iPhone and with it the paradigm of mobile/tablet computing. There are problems with this promise of counterculture and of technologists as removed from the status-quo they claim to disrupt. One is that, as Fisher [[96]] argues, in today's neoliberal capitalism, such a hero is almost impossible. As argued above, capitalism manages to absorb back into it countercultural aspirations and movements such as punk rock, protest imagery, critical design, hacking, and the arts [[7], [20], [94], [96]]. The other problem is that there are many forms of intervention besides disruption and going against the system, and if we address ourselves to the countercultural hero or the promise of individual empowerment, we might fail to appreciate, even altogether overlook, such alternatives. A vast literature on hacktivism and social movements in technology has studied in depth the ideals and aspirations of hackers, makers, tech producers, artists and activists to step outside and 
challenge existing structures. The goal of this paper is adjacent, in that it documents aspirations for alternatives. But the approach we take here also departs from this body of work in that it begins from the understanding that such aspirations to intervene are always already complicit, alongside, and partial. "Walking alongside" and "parasitic resistance" notice other modalities of intervention in and through technology production and design that begin from a deep recognition that there is no "outside the system."

\section{METHODS \& POSITION}

This paper draws from many years of fieldwork in China and Taiwan as well as our long-term engagements with the fields, methods and debates of design in social computing and beyond. Throughout the paper, we relate to various strands of prior work as is common for both ethnographic writing, and have hence avoided following the more common style of technical papers that separate theory, method, and findings. Our ethnographic research has spanned more than six years and has been focused on both the practice and discourse of making, designing, and innovation. We have conducted hundreds of hours of observations in a variety of spaces from coworking and hackerspaces to incubators, high school and university entrepreneurship training programs as well as events such as hackathons, maker faires, start-up weekends, and TEDx events. We have conducted many hours of interviews with different actors including but not limited to designers, engineers, open source and maker advocates, artists, policy makers, government representatives, urban planners, and investors. Our ethnographic research is multi-sited in nature in that it seeks to unpack how seemingly universal ideals of the global maker movement or open innovation are made in their particulars, while always retaining an eye towards entanglements with policy, discourse, and political economy. The research, then, took us not only to cities such as Shenzhen, Beijing, Shanghai, Taipei, Hsinchu, and Yilan but also to regions that they were tangled up with discursively and through global supply chain networks in Europe, the United States, and Africa.

An underlying goal in this research has been to unpack the shifts in creative industry development and the tech industry writ large, and the role that design and innovation practices in China and Taiwan play in these shifts. As is common in ethnographic writing, we resist the notion of claiming a positionality of "neutral observer" simply "recording the facts." Various interests and commitments have shaped both our engagements with China and Taiwan and our focus on sites of making, open source hardware, and histories and contemporary practices of industrial production. For one it is bearing witness - and trying to do justice - to China's shifting role in geopolitics in the past decade. For another, it is the ex-patriot's longing for a home that can never be returned to. For the other, it is an ever-deepening appreciation for a society on the edge.

As a research team, we share an IT research perspective that might broadly be construed as critical or humanistic, shaped by science and technology studies, cultural anthropology, design research, literary studies, and philosophy. We have been especially influenced by feminist and critical race studies within these domains, as well as East Asian and specifically Chinese studies, and aesthetics. Throughout our careers, we have spoken from these perspectives to the HCI and CSCW research communities, in hopes of contributing to the latter fields' own aspirations of enabling social justice, equality, and critical engagements in computing and society. Our time conducting ethnographic research, some but not all of which has been together, has helped us to notice and learn from ways that innovation and intervention with and through technology is significant, in both the sense of social impact and meaningfulness. We have also been motivated by 
the recognition that our own aspirations are in many ways aligned with people we have met in our research, even if articulated in ways different from our own professional lingua and sensibility as researchers. This is not to idealize them as in some ways more authentic or real instantiations of scholarly critique as Latour appears to celebrate design, but to notice moments of walking alongside despite and because of difference. It is also worth noting that the political conflict between China and Taiwan has at times contributed to intellectual tensions within our team, though none of us sees our research as directly connected to that conflict. This tension has, however, had the salutary effect that we have all learned to notice and speak more precisely and generously about the conflict and related matters, e.g., of democracy and political activism in China and Taiwananother instance where we have taken up Tsing's "noticing differently."

For the interested reader, we have detailed our ethnographic methods and long-term research in detail here: [[4], [9], [12], [13], [67], [68], [69], [70]]. A central commitment in our ethnographic engagements in China and Taiwan has been the close collaboration with our interlocutors, including co-authorship and the hosting of workshops aimed at bringing together hands-on making with critical intervention.

\section{MAKING CITIZENSHIP}

In 2011, a 23 year old young woman from Taiwan named Peggy Luo (羅珮琪), graduated from the top university in Taiwan, National Taiwan University, with a degree in accounting. She was looking at graduate school in the United States and planning for a bright future. On September 6, she received a phone call: her father had had a stroke on business in Vietnam. As an only child, Peggy had to step up. She put her own life on hold and turned her attention to taking care of her family. She had to learn how to do things like help her father file for early retirement and to collect the public benefits to which he was entitled. From her father's stroke in 2011 through 2014, Peggy continued to help her father, but now she faced two additional challenges: Her mother's eyesight increasingly became an issue. She discovered lumps in her own breasts. As she navigated hospitals, government policies, and insurance agencies for all three of them, she became overwhelmed to complete just one task: getting compensation for her father's first hospitalization and initial aftercare, which would reduce the overall medical expenses for her father from approximately $\$ 68,000$ USD to about $\$ 6,500$ USD. She would later summarize the challenges she faced as three issues: Relevant health-care info is not collocated; the info is written in incomprehensible legalese; and most of the published info is out of date.

In October 2012, she started a blog: afterthatday.blogspot.com (病後人生：一站式服務

網) (Tagline: “That day after, we're braver”). The blog had two objectives: (1) To make healthrelated information more transparent and accessible to patients and families (2) Reform laws, regulations, and policies to make them more friendly to people in need. She says, (“不知道、就沒 份”): “you can’t own what you are entitled to if you don't even know about it.” Peggy's blog far exceeded her expectations, with experts and regular readers contributing to her blog within a matter of months, her site hitting one million viewers by 2014 , and speaking invitations in the media occurring around the same time [[15]]. 


\subsection{The Sunflower Protest}

2014 was also a significant year in Taiwan, because of a youth rebellion that started with students taking over the Legislative Yuan in March of 2014 and ended, a year later, with lopsided opposition victories in Taiwan elections. The protest was about the KMT's (the then ruling party of Taiwan) attempted passage of a controversial trade agreement (i.e., the "Cross-Strait Service Trade Agreement" [CSSTA]) between Taiwan and the People's Republic of China (PRC) that would open up banking, healthcare, tourism, film, telecommunications, and publishing among others and make visas easier to obtained. The KMT had made certain promises to the opposition party (DPP) that it did not honor, which triggered the Sunflower Student Movement protest [[31]]. As we argued elsewhere [[12]], the Sunflower Student Movement was a protest of enfranchisement; that is, students were asserting themselves as subjects of Taiwanese governance. They saw themselves as subjected to the government (its laws, policies, institutions) and also are subjects of governing acts (i.e., agents of civic intervention). As Cole observes, the goal of the Sunflower Movement was not about overthrowing the government, but rather "to ameliorate existing institutions and force Taiwanese officials to meet the expectations of the public." [[26]]. Their literal demand was for the opposition party to have the opportunity to review the bill and for an apology from the president. But there was clearly a symbolic demand as well: for Taiwan's government to live up to the ideals of democracy, and for all of Taiwan to reckon with the collective voice of the rising generation so that it may be recognized as a political constituency.

During the protests themselves, students were aided by “台灣零時政府,” “g0v.tw” (pronounced "gov zero"), which is Taiwan's most influential hacker collective. Founded in 2012, g0v.tw is an online community that advocates information transparency (i.e., open data), focusing on developing IT platforms and tools for the citizens to participate in Taiwan. Substituting the "o" with " 0 " in gov, "g0v.tw" not only stands for rethinking the role that the government plays in society, but it also emphasizes the worldview of 0 and 1 in cultivating the new generation of citizens. In contrast to Anonymous, "g0v.tw" has a very diverse group of quasi-anonymized contributors, including web developers, programmers who do not hide their affiliations with international IT corporations (e.g., Google, Apple, Yahoo, HTC, Canonical, MediaTek, Trend, etc.). They include well known hackers (such as Audrey Tang who subsequently became Taiwan's first Digital Minister in 2016), academics, NGO/NPO activists, students, writers, designers, and other professionals among others. By 2015, g0v.tw had emerged as one of the top 3 civic-tech communities in the world (along with OKFN and Code for America) [[32]]. During the student protest, the collective rapidly constructed a sophisticated and systematic social computing infrastructure, provided a real-time protest support infrastructure, ran civic hackathons, as well as established an alternative media infrastructure, including broadcast capabilities and original news reporting and the use of scientific technologies and methods, to get around government-friendly news media.

The efficacy of the students' and g0v.tw's use of social media, ad hoc networks, mapping and visualization technologies distinguishes them from rioters and looters. They forged a generational identity coherent, powerful, and appealing enough to attract hundreds of thousands of young people, and as a collective, g0v.tw embodies and demonstrates their generational value proposition to Taiwan. IT and design were used in service of a protest, yet with the tacit blessing of the status quo: the Taiwanese government did not block Internet traffic or censor these initiatives, and it was an open secret that IT leaders were participating in support of the students. The Sunflower Student Movement effectively gave rise to a new Taiwanese subject - the civic-minded 
young generation willing to fight for a new generation of Taiwanese democracy. It also forged an invitation to hundreds of thousands of youth to join this public to stave off (in their view) the existential threat posed to Taiwan and its democracy by a neighboring superpower claiming Taiwan as its own.

\subsection{From Protest to Collaboration}

So it was that in 2014 Peggy joined g0v.tw in the hopes of turning her blog into a more collaborative and participative platform. But she would not stay there for long. A member of g0v.tw told us that Peggy's talent for making health information publicly available and participatively maintained would best be utilized in the very government they had been protesting. He and other g0v.tw members used their influence to help her begin a career working for the government, in the Ministry of Health and Welfare (衛生福利部) in 2015. Peggy explained to us that she transitioned from high profile member of a hacker collective to a government official, because she wanted to know "how system works, identifying pain points, and find ways to change from within." She agreed to work in the Ministry because she believes that it's not enough to always be critical of the government: "Unless the citizens know how government works and operates, we cannot be empowered to make changes and/or suggest feasible initiatives." She wants to be a bridge between the government and everyday citizens, so that government's efforts and policies are visible to the citizens; and that citizens' concerns can be represented to the government, with equal importance as those of industry leaders. To Peggy, “政府開竅，人人有責 (“everybody is responsible for a smart and knowledgeable government") and "it's important to take everyday citizens' perspectives into account when we implement policies." Another motivation is the fact that many of her college classmates are now civil servants and they are in her words, "among the most serious, hardworking, and smart people I know who just want to do good."

Today, at the Ministry of Health and Welfare, Peggy is evangelizing and implementing a platform called “join.gov.tw” (“公共政策網路參與平台”). This platform facilitates direct public engagement with different branches and offices in the central government, a collaborative initiative with the National Development Council (NDC), 國家發展委員會, the policy-planning agency of Taiwan's Executive Yuan established in January 22, 2014. The "join.gov.tw” initiative is based on the “ide@ Taiwan 2020 (創意臺灣) 政策白皮書” (“Creative Taiwan 2020 policy”) put forward by NDC in 2015 that stipulates the use of "collective wisdom gathered through the Internet to create a New Taiwan equipped with 'i-d-e-a' intelligent network by 2020 to shape future quality life for the people of Taiwan" which adheres to the core concepts of the quest for "the interests of all people," "cooperation between public and private sectors," and "innovative implementation," to carry out the policy with full vigor and urgency [[59]]. The "join.gov.tw" platform facilitates two-way communication between government offices and members of the public on regulatory matters. Through the platform, citizens of Taiwan can do the following 4 things: (1) propose (new rules/regulations or amend existing ones), (2) talk/discuss, (3) supervise, and (4) contact the ministers directly. The platform is a site of co-existence experiments for Peggy, the citizens, and the government to collaboratively prototype solutions that address how best for the citizens to work with the government, and how government can take people's appeals seriously to boost broader public engagement. 


\subsection{Hacking (Alongside) Democracy}

The Sunflower Movement, what we know about g0v.tw, and Peggy's comments about her classmates all suggest that she is not alone or particularly exceptional in contributing herself to Taiwanese democratic governance; she is part of a generational move. Her story is modest: she is a blogger turned government bureaucrat - hardly the stereotype of the political hacker. Yet in that generational move, idealism has overcome cynicism. Peggy's generation, combined with the prior generation's accommodation of her generation's rise to power, offers an image of democratic intervention and change, one of hope and respect for democracy, where agon exists but has not overthrown common purpose and even rational governance. One of the many ingredients in this image is the hacker collective, g0v.tw, of which Peggy might seem like a surprising representative. G0v.tw rose out of, and serves to champion, the open data/source movement in Taiwan. The democratizing values of open source, interestingly, are directly benefiting actual democratic governance. G0v.tw aims to influence government through public private partnership, and g0v.tw members regularly serve as consultants for various branches of the government. g0v.tw has a twopart motto, which reads, “不要問為什麼沒有人做這個, 先承認你就是沒有人。”“「沒有人」是

萬能的” (“Don't ask why nobody is doing the work, you are that nobody" and "Nobody" is allpowerful and all-capable."). Power comes from action, but not heroic acts of mythic proportions, but the much more mundane "work," which confers power.

In fact, Peggy is one of roughly a dozen g0v.tw members who serve in the government now. Collectively, those moving from g0v.tw to government are bringing not only individuals, but also values of open data, open democracy, civic participation, technological innovation, experimentation, and risk taking into Taiwan's policymaking and governance. G0v.tw is thus partially connected to but also partially divided from the government they have been critiquingthere is an "epistemological multiplicity" between the two in Strathern's and Mol's sense [[74], [89], [90]]. That is, they can be relentlessly critical of the government at times, but that criticism stays neither on the sidelines nor in the shadowy world of Wikileaks and Anonymous. Instead, it can become a form of labor within the government. Peggy's and the others' transitions helped them to be the government that they wanted. Just as they are capable of taking up an adversarial stance, they are also capable of setting it back down to work together. Again, Peggy is not alone in this: Audrey Tang, a software programmer and one of g0v.tw leading figures during Sunflower, became Digital Minister in Taiwan's Executive Yuan, where today she works on free/open software. The "openness" in open data/source is not just about making data transparent but about opening up/reimagining the citizen-government relationship.

Sociologist Joanna Latimer proposes a concept of being alongside, which is concerned with "intermittent and partial connections" between the human and the animal [[60], p. 77]. (Her objective is to develop a theory of "natureculture," which is not immediately relevant to our purposes here). We find Latimer's distinction between "being alongside" and "being-with" to be provocative and relevant to g0v.tw's relationship to Taiwan's government. Latimer [[60]] writes, Whereas [being with] insists on some kind of relationship in which each attends to the other to the benefit of the whole, [being alongside] preserves a sense of propinquity wherein [...] the register of concern is more that of preserving division-a conjoining of contingent and different 'parts,' none of which is simply subsumed into a whole. [p. 79-80]

Analogously, we are interested in the ways that hacking and government remain divided yet alongside, insofar as they remain diversely committed to at least some conception of 
democracy. One might even chart Peggy's trajectory as a move from "being alongside" (in which she built her blog and her audience independently from the government) towards a "being with," where her work shifted and became committed to benefitting the whole (in this case, Taiwan's democratic governance). G0v.tw played a central role in this transition. Yet g0v.tw's agenda has a complex relationship to the government. Again, it is not a shadow organization like Anonymous that positions itself as breaking laws and social norms for the higher purpose of speaking truth to power. Instead, g0v.tw contributes to governance through ad hoc formations of sophisticated confrontation and equally sophisticated participation and collaboration.

\section{LABORATORY TO ACT IN UNCERTAIN TIMES}

In 1997, Kent Zhang got an offer from his employer, the Taiwanese contract manufacturer Foxconn, to move from Taiwan to Shenzhen, China, where the company had been setting up a new facility in Longhua, a district in the Northern parts of the city. Kent had been working as an engineer at Foxconn in Taiwan and this new job was in management, giving him more responsibility, his own engineering team as well as funding for his family to relocate to China. "This was a very run-down area of Shenzhen back then," Kent reflected in an interview in 2015, "The Foxconn factory was made out of galvanized iron sheets. We were only 1,000 people at that time. I was one of 23 Taiwanese managers working there. This really shows the development of Foxconn. Today, Foxconn has 100,000 working there." Since 2016, Longhua is its own district and one of the main production bases in Shenzhen, but also home to a series of new high-end residential areas. It is conveniently connected via a subway line to other parts of the city, including the airport, the electronic markets of Huaqiangbei, shopping and entertainment.

By the late 1990s and the time Kent relocated his family to Shenzhen, the city was at the peak of its rapid economic and social self-transformation into -- what the government envisioned to become - one of China's key high-tech industries. By that time, the region's experiment in economic opening had already long been declared a success. It had been two decades earlier, in 1978, when Deng Xiaoping declared Shenzhen one of four Special Economic Zones that should carry out an experiment for China as a whole; economic opening and the adoption of capitalist market processes. Shenzhen constituted a laboratory, so to say, where Foreign Direct Investment (FDI), privatization of state run enterprises, and entrepreneurial activity were actively encouraged. The key challenge was how to legitimize the uptake of such capitalist values and ideologies that the CCP (China Communist Party) had strongly opposed throughout the previous decades. The challenge, in other words, was not only how to become capitalist, but also how to become postsocialist. Containing this experiment in regional zones like Shenzhen enabled a gradual shift from a socialist system of lifetime employment, shared resources, work units, and state-run enterprises towards the informalization of work, unstable employment, and the legitimization of surplus value creation and personal enrichment [[57]]. "To get rich is glorious," Deng Xiaoping famously declared during his 1982 visit to Shenzhen.

Political scientist Mary Gallagher shows that what made the experiment of Shenzhen work had in part to do with an approach of gradual transition that kept the old system in place as new practices and values were being introduced over time [[47]]. FDI was introduced as a dual system that did not replace the old system of state operated enterprises, but created a system of competition between old and new entities. Two modes of labor, socialist and capitalist, coexisted, with FDI establishing a space outside the socialist sectors. Over time, because of pressures of competitive liberalization and market competition, a process of "contagious capitalism" began taken place, 
Gallagher shows, where capitalist practices were adopted across distinct ownership boundaries. Much of the early FDI came from Hong Kong and Taiwan, often driven by Chinese family lineages, and was later followed by American and European investment, coinciding with the Western outsourcing boom. Fast forward to today, Shenzhen is not only home to large contract manufacturers such as Foxconn, but also to thousands of smaller-scale design houses. Shenzhen, in other words, covers what many in local industry terms refer to in Mandarin Chinese as chanyelian ( 产业链 the whole supply chain of electronics production). A generation of engineers and designers like Kent has built their careers alongside and through Shenzhen's experimentation with capitalist processes and the build-up of a supply chain that is today celebrated by Western commentators and tech media outlets as Shenzhen's key regional advantage in global tech innovation [[66]].

Kent retired in 2011, but stayed in Shenzhen, and today runs an accelerator program called "Maketopia." The people who join the program are of his son's age, in their mid-twenties to early thirties. This younger generation has turned to the region to make their careers in an economy of venture labor [[77]]. For them, Shenzhen is once again a laboratory to adjust to - in this case - not only regional but also global shifts of industries, work and labor. Over the last years, a growing number of designers and engineers, many of whom advocate an open source hardware and maker approach, have begun to take an interest in Shenzhen [[66], [69]]. They have proliferated an imagery of Shenzhen that applies ideas of peer production and hacking to processes of the political economy and industrial production. They are from all over - from other parts of China, Taiwan, the United States, Europe, Africa, Hong Kong, and many other regions. While they come to Shenzhen with varying motivations, many of them expressed - in one way or another -- an aspiration to intervene in established workings of technology industries and existing economic structures.

Many of them witnessed an increasing precarization of their work. While in the 1990s and early 2000s, information technology was celebrated as enabling the rise of a global creative class and knowledge economy that would free people from labor exploitation in the factory [[98]], by the time Shenzhen gained traction in global maker discourse, a growing suspicion of such earlier promises had grown. Making and open source hardware was appealing to this generation of tech producers, because they associated with it an ability to intervene into the inner workings of both the black box of consumer electronics and precarious work conditions [[66], [69]]. Shenzhen, to them, appeared promising, because it would allow to act on these aspirations to intervene. It would allow them to not only hack prototypes and devices, but also "hack the supply chain" of contemporary industrial production. The underlying idea was that by hacking supply chains one could also regain a level of control over the means of production, typically concentrated in the hands of large corporates [[66]].

\subsection{Riding the Wave}

In 2015, the Shenzhen-based open source hardware company Seeed Studio released a DIY (do it yourself) phone kit, which the company positioned in its kickstarter campaign as the latest toolkit to "hack the electronics supply chain of Shenzhen." The kit would allow people not only to design and build their own unique phone, but also to begin learn about some of the components and elements of Shenzhen's supply chain. Seeed Studio was founded by Eric Pan in 2008, and has become one of the crucial entities that bridges between a global network of open source hardware and maker advocates and Shenzhen's supply chain and manufacturing culture. The company had grown quickly after its inception from a two-person business into an internationally renowned open source hardware production house in part because it had made its task to map and make accessible 
Shenzhen's supply chain and economies of scale. In 2014, Eric Pan was featured on the cover of Forbes Magazine as one of China's 30 under 30.

At a conference on "rethinking technology innovation," which we co-hosted with colleagues from the HCI lab at the University of Salzburg that same year [[46]], we had invited Eric to reflect on the past years of transformation in open source hardware, making, and manufacturing and beyond. Eric's business was going well, the company had just expanded to a size of 400 employees. But Eric's story about his own path and the company's direction was different from the modality of pitching and branding of one's work that has become so pervasive in the fields of design, engineering, and technology more broadly. At the conference, he talked openly about the hype that had been generated around making, to which his company had partially contributed but also benefited from. "It is like riding a wave," he explained to the 40 or so people that had gathered from the fields of HCI, design, engineering, and digital fabrication that day, "you don't know what happens next. You don't know how long it will last. It might all of a sudden go flat, swallow you, or lift you up even further. So all you can do is keep riding the wave." The hype should continue.

A year after our gathering in Salzburg, the Chinese prime minister Li Keqiang visited the hackerspace Chaihuo (柴火) in Shenzhen that Eric Pan had co-founded with Kevin Lau in 2011. The Chinese prime minister was so intrigued by what he saw at the small hackerspace that he declared a new national policy only weeks later that stipulated making as a model to bring entrepreneurship and innovation thinking to the masses [[66]]. Eric and many of the other making and open source hardware advocates in China at that time felt ambivalent about the sudden official support. While they agreed that generally such support could be a good thing and help proliferate an approach of tinkering and experimentation into education and business culture, many felt that a national policy might undermine the premise of making as evolving from the grassroots and individual creativity.

Li Keqiang's endorsement of making to cultivate what the government ended up calling "mass entrepreneurship," "mass makerspaces," and "mass innovation" fits squarely within a political program that has been set in motion since Xi Jinping took over the leadership of the CCP in 2012. Under Xi's leadership, the CCP began articulate and implement a program to address the slowdown of China's rapid economic development, which had helped guarantee both a level of social stability and the party's leadership the previous decades. What the CCP began calling "China's new normal" described a fairly drastic shift from this earlier model of rapid GDP growth into a model of stability and slow-down aimed at developing "a moderately prosperous society" [[56]]. Xi's articulation of the so-called "China dream" and "great China" is aimed at articulating an approach towards continuous progress that distinguishes China from the West, and the United States in particular. A key aspect of this new political discourse is a renewed emphasis of socialist ideals. What differentiates China's approach to modernization and globalization from the West, so Xi's official line goes, is its historical roots in socialism. China's gap between rich and poor, in official rhetoric, is often framed as an unfortunate but inevitable byproduct of the past economic development and capitalist experimentation. Xi's new economic reform program is articulated as addressing these inequalities of the past and benefiting a broad majority of people. Li Keqiang's mass makerspace policy fits squarely within this larger discourse and government self-branding of "benefitting the people.

Shenzhen has drawn much excitement amongst open source and maker advocates from abroad. It is seen by many as a laboratory to adopt to capitalist structures of precarious work in the tech industry by learning about the inner workings of economization and marketization [[66]]. 
Shenzhen, in other words, was seen as a way to learn how to become proficient in capitalist modes of speed and agility, and by extension to intervene in its very processes. Here, a longing for intervention into capitalist processes is enacted not from a position of distant critique, but through a myriad of parasitic resistances, with the state feeding off of the flurry of makers the city attracted who in turn fed off the city's modality of speed, deemed so crucial amidst a pervasive acceleration of markets and life itself [[97]]. Adjacent to the government's endorsement of making to rework China's economic processes, many foreign open source hardware advocates saw Shenzhen as enabling them to rework global capitalism from within. Not without irony, the mass maker policy appears to be aimed at implementing exactly what making had promised all along: to democratize tech production and innovation. The appropriation of making, in other words, offers the CCP a kind of laboratory to tinker with China's approach to global capitalism, branded as in line with socialist core values. In a move adjacent to the adoption of FDI to cultivate experimentation with capitalism alongside (and despite) socialism in the 1980s and 90s [[47]], the CCP appropriates making today CCP to instill in its citizens urgencies and even desires to upgrade amidst drastic economic and geopolitical shifts today.

\section{2. Seeing the Future}

At the 2015 Shenzhen Maker Faire, we met Monica Shen, one of the co-founders of Maker Bar in Taipei. Maker Bar, she explained, was about to close as it had become increasingly difficult to sustain the volunteer and unpaid labor necessary to keep the community space going. Monica was debating between staying in Taiwan, moving to Silicon Valley or moving to Shenzhen. A couple of months later, we met Monica again. She had moved to Shenzhen and taken on a new job at Seeed Studio, working alongside Eric Pan to set up a new collaborative space called xFactory.

"Taiwan means not seeing or knowing the future," she explained. "There is a slowness to it. It is not heading anywhere. I really wanted this to work, you know. To make Maker Bar work. The Taiwanese community has played a big role in building Shenzhen in the past. And so i was thinking I can play a role here in Shenzhen. Here, at Seeed Studio, I can create an environment where the feel is not like making is a political project like in Taiwan. It would have been impossible to build xFactory in Taiwan. It would have been impossible to bring something like this to the market. In Taiwan, it's always political. You have this small group in the DPP party that keeps pushing to not do anything with China. It's easy to lose sight of what's important, if you don't see the bigger picture, if you are locked up in an old ideology. China is always lurking as that big neighbor, so in Taiwan you can't see the future. Where I stand here, nobody talks about politics in Shenzhen, you focus on getting stuff done."

What Monica articulated here was something we heard over and over. Shenzhen offered many people who had been working in the creative and tech industries abroad a sentiment of "getting stuff done." This sentiment of "actionability" was crucial to many of the maker and open source advocates who argued that corporate monopoly and capitalist structures had removed people's ability to intervene. Learning from and intervening in supply chains and markets in Shenzhen was understood as a project freed from political ideology and by extension providing people with the very ability to be political and intervene in geopolitical processes of production. For Monica, Shenzhen meant to act despite capital P politics. Shenzhen and Taiwan's historical and continuous economic and social codependency from early FDI to numerous family businesses that connect the two regions figures centrally in contemporary political discourse in both regions. Under the current leadership of the DPP in Taiwan, acknowledging past and continuous economic and other dependencies on China is highly contentious for some, as Monica alluded to in her remarks. 
At the same time, the CCP under Xi's leadership continues its further expansion of power in Asia with renewed strength and self-assurance due to its rising political and economic stature globally, at a time when the US is perceived as being in retreat [[79]]. Albeit Shenzhen could be seen as the region where China's and Taiwan's co-dependencies are most difficult to disentangle, it has also emerged as an imaginary where certain people can -- for now -- see the future, live on and experiment with alternatives alongside such larger geopolitical tensions and conflicts.

Kent's, Eric's, and Monica's personal and professional lives are each tangled up with a complicated history and continuous processes of experimental governance in Shenzhen. Markets, state, and citizens, here, come together through a myriad of co-dependencies - a walking alongside through difference and parasitic resistance. Their life choices and the changes that have unfolded in Shenzhen over the last 30 years fold together in ways that take us beyond the quick and sensational stories of personal success, economic development and modernization. Instead, they invite us to notice differently by drawing out ambivalent attachments and yearnings for alternatives, even if only partially accomplished.

\section{NOTICING DIFFERENTLY}

Fisher writes that we "...face something of a paradox: we confront the unprecedented urgency of radical action when there is nowhere to go and no single structure of domination to resist-when a micropolitics of disruption is simultaneously not enough, yet all that seems to be on offer" [[41]]. We argue that this problem is shared not only be designers and activists, but also by scholars, academics, and researchers. Social computing researchers face a classic dilemma between the properly epistemic and the political outcomes of research, as if politics is either irrelevant to, or even downright compromising of, knowledge production [[13]]. This dilemma seems to persist even in a research era in which scholars, researchers, designers, engineers, and scientists have expressed renewed interest in utilizing their skills to intervene and conceive of alternatives to current economic and political processes.

There are two common reactions to this dilemma-in social computing, design, and beyond. The first one is to avoid tackling large-scale and systemic issues of inequality and uneven power relations, and to focus instead on concrete solvable problems and the micro. The proposal, here, is to start small and work up: a view of interaction, for example, as composed of micro actions, from the early work on cognition to the heyday of ethnomethodology's influence to Binder et al.'s "democratic experiments in the small." Common to all of these is a commitment to design practice and research at a small scale--either the scale of the give and take of actual interactions--a scale so micro that politics is hard to see at all--or at the scale of the local intervention, e.g., [[63], [39]]. A second common reaction has been to approach complex societal and economic issues as problems that can be solved via technological solutions [[2], [68], [83]]. This tendency to address societal and economic issues with computational and/or otherwise "scientific" methods and techniques has, arguably, helped legitimize the comparatively young interdisciplinary fields of social computing [[29]].

Across these two approaches, the positionality of the designer, researcher or scientist is typically understood as "outside" structures of the political economy [[54]]. In contrast, a figure that has historically been granted political efficacy in computing is the countercultural hacker that has long shaped technological imaginaries about what constitutes resistance in the digital age, i.e. an oppositional and antagonistic stance embodied in the individual (often masculine) renegade [[38], [96]]. While granted political agency, absent from the narrative of the countercultural hero, 
among other things, is the notion of exclusion and difference. Design thinking and human-centered design as well as open design, DIY, making, and open innovation promise the empowerment of "everyone." Such ideals of universal empowerment mask differences along gender, racial and class lines that preclude vulnerable populations and minorities to benefit the same way [[28], [35]].

Our goal in this paper has been to account for subjectivities of intervention that do not fall into these more familiar frames of what counts as technological counterculture, what carries potential for resistance, and what techno-scientific rigor looks like. Thinking through and working with feminist sensibilities alongside our ethnographic research has enabled us to notice subjectivities in design differently, i.e. how design operates within or alongside (but not simply against) various forms of power. Peggy Luo, Eric Pan, Kent Zheng, and Monica Shen are thus not best described as rebels, heroes, or merely coopted. Their stories are full of contradictions and ambivalences, and so they represent subjectivities that are equally complex. G0v.tw alumnae Peggy Luo's and Audrey Tan's respective positions within government are examples of unexpected conviviality. (Even more unexpectedly convivial: the woman who held Audrey Tan's job in government before 2016's wave election has now taken Tan's former role in g0v.tw). Even so while g0v.tw and the government share a commitment to democracy, what they value in it, and how they pursue it as a concrete agenda, are often very much at odds. Peggy Luo's new democratic platform reflects g0v.tw's values, but it has a very narrow scope in Taiwan's government and remains outside of the mainstream. Former g0v.tw hacker and now Minister without Portfolio Audrey Tan still embraces open source computing principles and is opening up government data to the public; even so, entrenched political actors, seeking reelection and other agendas, do not share her commitment to transparency or her f/loss-shaped ethical worldview.

Fisher's parasitism suggests an asymmetrical interdependency, where the parasite depends on the host in ways not true (or less true) than the other way around. She continues, "the parasite's resistant potential is inextricable from the concessions it makes in order to survive within the host milieu" [[41]]. For Eric Pan and Monica Shen, whose work has been tangled up with the Western imaginary of a newly innovative Shenzhen [[69]], the tone of modern progress and futurity is somewhat dubious. They neither refute it nor do they actively propagate it. Eric's notion of "riding the wave," for instance, articulates a positionality that is not a radical counter-move, but creating an "opening in the system as long as it can" [[41]]. And Monica's hopes and search for "actionability" in Shenzhen is rooted in - rather than antagonistic to-her past in Taiwan.

These subjectivities in technology design resemble "the art of resistance in an age of cooption," a "symptomatic response to the waning sense of agency in contemporary political life" [[96]]. They emerge, Fisher argues, in a moment when "political tools on hand appear co-opted in advance" and the very act of resistance already includes its potential co-option - a moment marked by the increase in precarious conditions of work and labor that cuts across class, race, and gender [[30], [45], [72], [94]], by a climate of uncertainty and the waning power of the United States, and the acceleration of a modality of neoliberalism capitalism, which "absorbs its critiques as yet another site of surplus value creation" [[20]]. This does not make people passive victims of a supposed all-powerful system. While strands of neoliberal capitalism have since Margaret Thatcher's famous phrase "there is no alternative" proliferated an ideology of inevitability, Peggy, Monica, Kent, and Eric do indeed work through alternatives - and yet these alternatives do not exist outside or separate from, but rather mirror and distort, their neoliberal context of entrepreneurial optimism and self-actualization.

Various scholars before us have urged to reconsider critiques of the political economy [[72], [76], [81], [84]]. Yet, as we have stated at the beginning, technology researchers are caught 
in a dilemma of longing for political efficacy on the one hand and a hesitation to take on an overtly political or critical stance in IT fields on the other. This is where, we believe, a critique of the political economy as developed by feminist and critical race studies scholars can help to step sidewise and outside of binaries of critique vs. co-option, critique vs. action, system vs. resistance. What can a feminist critique of technology and its relationship to political economy contribute? A key take away message, as one of the reviewers of this paper urged us to articulate, is that an interventionist and politically engaged computing scholarship can and perhaps even should begin from a commitment to noticing differently rather than falling back on established categories of what counts as interventionist, countercultural, and technological. This paper has contributed two analytics from feminist and critical race studies to further build up a repertoire for interventionistoriented social computing scholarship: the notions of "walking alongside" and "parasitic resistance," each of which has enabled us to appreciate modes of intervention otherwise seldom recognized as such. In so doing, this paper aims to contribute a feminist critique of the political economy that can create further openings in the fields of social computing and beyond and legitimize stances that have not come easy in our research community: a stance that openly avows its own political and ethical interventions and commitments, that practices an art of noticing differently [[94]], and finally that accepts that specific interventions might not add up to a robust alternative that authentically challenges the status quo; it might instead "walk alongside" it, caught up in parasite tangles [[60], [41]].

Cultural geographer David Harvey [[49], p.91] stresses conceiving of "spaces of hope" that do "not separate out the local, concrete, and cultural intervention" from macro-scale and uneven geographical developments. He poses the question: "how do you transform a local struggle with particular issues onto a completely different scale of analysis and politics so it becomes visible and politically interesting?" The current era of neoliberal globalization, he argues, has bred on the one hand a distrust of utopian thought, and on the other hand a "nostalgic longing" for it. This longing is embodied in a turn towards local, community, and small-scale intervention. Harvey considers this longing as carrying a dark side, as "communities often exclude, define themselves against others, internalize surveillance and social controls. communities have often been a barrier rather than a facilitator of social change." The role of noticing such longing for politically efficacious technology research and design practices falls in part on technology researchers and designers; that is one sense in which we view our work as political. Much of our work is funded by industry and government agencies, in part supporting their agendas, including economic growth and national strength. It is possible for researchers to attempt to stand outside of those dynamics, to research without funding and to offer a critique, yet such a stance is often structurally marginalized and risks cooption anyway. We propose instead start from a position that acknowledges one's complicity, including our own longings for a world that is otherwise.

Our turn to the stories of Peggy, Eric, Monica, and Kent is thus also an inquiry into how technology research and design might serve the noticing of spaces of hope in the gaps and fissures of global capitalism, even if fleeting and incomplete. Their work cannot be accounted for as local interventions; each is situated within and responding to networks of globally shifting power, including the continuous tensions in China-Taiwan relations, the trade and investment relations between China, Hong Kong, Taiwan, and Hong Kong that facilitated Shenzhen's growth in the 1980s, or the waning power of the United States. Peggy's, Monica's, Eric's and Kent's stories cannot be reduced to the passive outcome of any of these macro-scale developments; their unique personal histories and personalities also shape what each has achieved. But their work is also not independent of macro developments; none has the potential to overthrow them. Through their 
navigations of emerging technologies and/in global politics, they-like us - are experimenting with new ways to effect change with technology; we are all longing for intervention in an era of "no alternative."

\section{ACKNOWLEDGEMENTS}

We thank all of our participants, as well as Robin Brewer, Julie Hui and Florian Schraub for comments on drafts. We also thank our long-term research collaborators Anna Greenspan, Ingrid Fischer-Schreiber, David Li, Peggy Luo, Eric Pan, and Monica Shen. This work was in part supported by the National Science Foundation under awards 1617898, 1513596, 1516204, and 1513604, and the Lieberthal-Rogel Center for Chinese Studies at the University of Michigan.

\section{REFERENCES}

[1] Meryl Alper. 2017. Giving Voice. Mobile Communication, Disability, and Inequality. MIT Press.

[2] Morgan Ames, Daniela Rosner, and Ingrid Erickson. 2015. Worship, Faith, and Evangelism: Religion as an Ideological Lens for Engineering Worlds. In Proceedings of the 18th ACM Conference on Computer Supported Cooperative Work \& Social Computing, CSCW'15, pp. 69-81.

[3] Morgan Ames, Jeffrey Bardzell, Shaowen Bardzell, Silvia Lindtner, David Mellis, and Daniela Rosner. 2014. Making cultures: Empowerment, participation, and democracy —or not? CHI2014 EA.

[4] Seyram Avle and Silvia Lindtner. 2016. Design(ing) here and there: Tech entrepreneurs, global markets, and reflexivity in design processes. In Proceedings of the SIGCHI Conference on Human Factors in Computing Systems (CHI'16), 2233-2245.

[5] Seyram Avle, Silvia Lindtner, and Kaiton Williams. 2017. How methods make designers. In Proceedings of the SIGCHI Conference on Human Factors in Computing Systems (CHI '17), 472-483.

[6] Liam Bannon and Pelle Ehn. (2013). Design: design matters in participatory design. In Jesper Simonsen and Toni Robertson (eds.). Routledge International Handbook of Participatory Design. Routledge.

[7] Jeffrey Bardzell and Shaowen Bardzell. 2013. What is "critical” about critical design? Proc. of CHI'2013. ACM: New York.

[8] Jeffrey Bardzell and Shaowen Bardzell. 2015. The User Reconfigured: On Subjectivities of Information. Aarhus Series on Human Centered Computing, 1(1), 12. https://doi.org/10.7146/aahcc.v1i1.21298

[9] Jeffrey Bardzell, Shaowen Bardzell, Cindy Lin, Silvia Lindtner, and Austin Toombs. 2018. HCI's Making Agenda. Foundations and Trends in Human-Computer Interaction

[10] Jeffrey Bardzell, Shaowen Bardzell, and Mark Blythe, eds. 2018. Critical Theory and Interaction Design. Cambridge, MA: The MIT Press.

[11] Shaowen Bardzell 2010. Feminist HCI: Taking stock and outlining an agenda for design. In Proc. of CHI'10. ACM: New York.

[12] Shaowen Bardzell 2014. A protest of enfranchisement. Invited talk at Intel ISTC Social All Hands meeting.

[13] Shaowen Bardzell 2018. Utopias of Participation: Feminism, Design, and the Futures. ACM Transactions on Computer-Human Interaction (TOCHI). ACM.

[14] Shaowen Bardzell and Jeffrey Bardzell. 2011. Towards a Feminist HCI Methodology: Social Science, Feminism, and HCI. Proc. of CHI2011.

[15] Shaowen Bardzell. 2017. Accidental Activists. Panel on Social Justice at ACM CSCW (February 2017)

[16] Seyla Benhabib. 1992. Situating the Self: Gender, Community, and Postmodernism in Contemporary Ethics. Routledge.

[17] Nicola Bidwell. 2016. Decolonizing HCI and interaction design discourse. Some Considerations Planning AfriChi. XRDS: Crossroads, The ACM Magazine for Students - Cultures of Computing, Vol. 22, Issue 4, pp. 22-27.

[18] Thomas Binder, Eva Brandt, Pelle Ehn, and Joachim Halse. Democratic design experiments: Between parliament and laboratory. CoDesign 11, 2015, Issue 3-4.

[19] Susanne Bodker, Pelle Ehn, J. Kamersgaard, Morten Kyng, and Yngve Sundblad. 1987. A utopian experience. In G. Bjerknes, P. Ehn and M.Kyng (eds.) Computers and democracy: A Scandinavian Challenge. Aldershot: Avebury, 25178.

[20] Luc Boltanksi and Eve Chiapello. 2007. The New Spirit of Capitalism. Verso.

[21] Tim Brown. 2008. Design Thinking. Harvard Business Review. 
[22] Burnett, Margaret M. 2010. End-User Software Engineering and Why it Matters. In JOEUC, 22 (1) pp. 1-22.

[23] Giulia Calabretta, Gerda Gemser, Ingo Karpen. 2016. Strategic Design: 8 Essential Practices Every Strategic Designer Must Master. BIS Publishing.

[24] Nancy N. Chen and Lesley A. Sharp (eds) 2014. Bioinsecurity and Vulnerability. SAR Press.

[25] Wendy Chun. 2016. Updating to Remain the Same. Habitual New Media. MIT Press.

[26] J. Michael Cole. 2014. Black Island: Two Years of Activism in Taiwan.

[27] Alan Cooper. 1999. The Inmates are Running the Asylum. Carmel, IN: Sam's Publishing.

[28] Tawanna Dillahunt and Malone, A.R. The Promise of the Sharing Economy among Disadvantaged Communities. Proceedings of the ACM 32nd international conference on Human factors in computing systems (CHI), 2015.

[29] Paul Dourish. 2006. Implications for Design. Proc. of the SIGCHI Conference on Human Factors in Computign Systems, pp. 541-550.

[30] Nick Dyer-Whiteford. 1999. Cybermarx. Cycles and Circuits of Struggle in High Tech Capitalism. University of Illinois Press.

[31] Rong-xing He. 2014. The Age of Student Movement: From the Wild Lily Student Movement in 1990 to the Sunflower Movement in 2014 (學運世代：從野百合到太陽花). Reading Times Publisher.

[32] Chen-ling Hong (2015). Sunflower Movement, New Citizenry, and New Media. (我是公民，也是媒體：太陽花與新 媒體實踐). Lotus Publishing.

[33] Carl DiSalvo. 2012. Adversarial Design. MIT Press.

[34] Paul Dourish and Scott Mainwaring. 2012. Ubicomp's Colonial Impulse. Proc. ACM Conf. Ubiquitous Computing Ubicomp 2012 (Pittsburgh, PA), 133-142.

[35] Lynn Dombrowski, Garcia, A.A., and Despard, J. 2017. Low-Wage Precarious Workers' Sociotechnical Practices Working Towards Addressing Wage Theft. In Proceedings of the 2017 CHI Conference on Human Factors in Computing Systems (CHI '17). ACM, New York, NY, USA, 4585-4598.

[36] Anthony Dunne. 1999. Hertzian tales: electronic products, aesthetic experience and critical design. London: Royal College of Art

[37] Terry Eagleton. 2004. After Theory. New York: Basic Books.

[38] Paul Edwards. 1997. The Closed World. Computers and the Politics of Discourse in Cold War America. MIT Press.

[39] Pelle Ehn. 1988. Work-Oriented Design of Computer Artifacts. Stockholm: Arbetslivscentrum.

[40] Pelle Ehn, Elisabet M. Nilsson, \& Richard Topgaard. 2014. Making futures: Marginal notes on innovation, design, and democracy. MIT Press.

[41] Anna Fisher. Forthcoming. The Play in the System: Parasitism Performance and the Art of Resistance from Within (current title).

[42] Sarah Fox, Amanda Menking, Stephanie Steinhardt, and Shaowen Bardzell. 2017. Imagining intersectional futures. ACM CSCW and Social Computing (CSCW).

[43] Sarah Fox, Jill Diamond, Lilly Irani, Michael Muller, Shaowen Bardzell. 2017. Social Justice and Design: Power and oppression in collaborative systems. CSCW'17 Companion of the 2017 ACM Conference on Computer Supported Cooperative Work and Social Computing, pp. 117-122.

[44] Batja Friedman, Kahn, P. H., Jr. and Borning, A. Value sensitive design and information systems. In P. Zhang and D. Galletta (eds.), Human-Computer Interaction and Management Information Systems: Foundations. M.E. Sharpe, Armonk, NY, 2006.

[45] Christian Fuchs. 2014. Digital Labor and Karl Marx. Routledge.

[46] Verena Fuchsberger, Silvia Lindtner, Martin Murer, Manfred Tscheligi. 2016. Rethinking Technology Innovation. Factories, Fabrication, and Design Research, September 28-30, 2015, Summit Report: https://hci.sbg.ac.at/sites/ffdr/

[47] Mary Gallagher. Contagious Capitalism. Globalization and the Politics of Labor in China. Princeton University Press.

[48] Jean Hardy and Silvia Lindtner. 2017. Constructing a Desiring User. In Proc. of CSCW.

[49] David Harvey. 2000. Spaces of Hope. University of California Press.

[50] Gillian R. Hayes. 2011. The relationship of action research to human-computer interaction. ACM Trans. Comput.Hum. Interact. 18, 3, Article 15 (August 2011), 20 pages. DOI: https://doi.org/10.1145/1993060.1993065

[51] Lilly Irani, Janet Vertesi, Paul Dourish, Kavita Philip, and Rebecca E. Grinter. 2010. Postcolonial computing: a lens on design and development. In Proceedings of the SIGCHI Conference on Human Factors in Computing Systems (CHI '10). ACM, New York, NY, USA, 1311-1320. DOI: https://doi.org/10.1145/1753326.1753522

[52] Lilly Irani and Six M. Silberman. 2016. Stories We Tell About Labor: Turkopticon and the Problem with 'Design'. Proceedings of the 34th Annual ACM Conference on Human Factors in Computing Systems. ACM.

[53] Lilly Irani. 2015. Hackathons and the Making of Entrepreneurial Citizenship. ST\&HV, Vol 40, Issue 5.

[54] Steve Jackson, Tarleton Gillespie, Sandy Payette. 2014. The Policy Knot: Re-integrating Policy, Practice and Design in CSCW Studies of Social Computing. In Proc. of ACM CSCW'14, pp. 588-602. 
[55] Lucy Kimbell. 2015. Rethinking Design Thinking: Part I. Design and Culture, The Journal of the Design Studies Forum, 3:3, 285-306.

[56] Kroeber, A. 2016. China's Economy. What Everyone needs to know. Oxford University Press.

[57] Kuruvilla, S., Lee, C.K., and Gallagher, M.E. (eds). 2011. From Iron Rice Bowl to Informalization. Markets, Workers, and the State in a Changing China. Cornell University Press.

[58] Morgen Kyng and L. Mathiassen (1982). Systems development and trade union activities. In N. Bjorn-Andersen (ed.). Information Society, For Richer, For Poorer. Amsterdam: North-Holland, 247-60.

[59] ide@ Taiwan 2020 Policy: White Paper. https://tinyurl.com/ydeo94sb Retrieved 12/31.2017.

[60] Joanna Latimer (2013). Being alongside: Rethinking relations amongst different kinds. Theory, Culture, and Society $30(7 / 8), 77-104$.

[61] Bruno Latour. 2004. Why has critique run out of steam? From matters of fact to matters of concern. Critical Inquiry 30 (winter). 225-248.

[62] Bruno Latour. 2008. Cautious Prometheus? A few steps towards a Philosophy of Design. In Fiona Hackne, Jonathn Glynne and Viv Minto (editors) Proceedings of the 2008 Annual International

[63] Christoph A. Le Dantec, R. G. Farrell, J. E. Christensen, M. Bailey, J. B. Ellis, W. A. Kellogg, and W. K. Edwards. Publics in Practice: Ubiquitous Computing at a Shelter for Homeless Mothers. In Proc. of CHI2011, pages 1687-1696, ACM: New York

[64] Ruth Levitas. 2013. Utopia as Method: The Imaginary Reconstitution of Society. Palgrave Macmillan.

[65] Jean-Francois Lyotard. (1984). The Postmodern Condition: A Report on Knowledge. University Of Minnesota Press

[66] Silvia Lindtner. 2017. Laboratory of the Precarious: Prototyping Entrepreneurial Living in Shenzhen. WSQ Vol. 45, Nr. 3\&4, pp. 287-305.

[67] Silvia Lindtner and Seyram Avle. 2017. Tinkering with Governance. Technopolitics and the Economization of Citizenship. Proceedings of the ACM on Human-Computer Interaction, Vol. 1, No. 2, Issue CSCW, Article 60.

[68] Silvia Lindtner, Shaowen Bardzell, and Jeffrey Bardzell. (2016). Reconstituting the Utopian Vision of Making: HCI after Technosolutionism. Proc. of CHI2016.ø

[69] Silvia Lindtner. Forthcoming. The Promise of Making. Prototyping Entrepreneurial Living in China's New Normal. Princeton University Press.

[70] Silvia Lindtner. Hacking with Chinese characteristics: the promises of the maker movement against China's manufacturing culture. Science, Technology, \& Human Values 40, no. 5 (2015): 854-879.

[71] Silvia Lindtner, Anna Greenspan and David Li. 2015. Designed in Shenzhen: Shanzhai manufacturing and maker entrepreneurs. In Proceedings of the 5th Decennial Aarhus Conference on Critical Alternatives, 85-96.

[72] Angela McRobbie. 2016. Be Creative. Making a Living in the New Culture Industries. Polity.

[73] Ezio Manzini. 2015. Design, When Everybody Designs. MIT Press.

[74] Annemarie Mol. 2002. The Body Multiple: Ontology in Medical Practice. Duke UP.

[75] Lisa Nakamura. 2007. Digitizing Race: Visual Cultures of the Internet, University of Minnesota.

[76] Bonnie Nardi and Hamid Ekbia. 2018. Heteromation and other stories of computing and capitalism. MIT Press.

[77] Gina Neff. 2012. Venture Labor. Work and the Burden of Risk in Innovative Industries. MITPress.

[78] Aiwah Ong. 2006. Neoliberalism as Exception: Mutations in Citizenship and Sovereignty. Durham, NC: Duke University Press.

[79] Evan Osnos. 2018. Making China Great Again. As Donald Trump surrenders America's global commitments, Xi Jinping is learning to pick up the pieces. The New Yorker, 01/08/2018.

[80] Victor Papanek. 1985. Designing for the Real World: Human Ecology and Social Change. Academy Chicago Publishers.

[81] Trebor Scholz. 2016. Uberworked and Underpaid. How Worker are Disrupting the Digital Economy. Polity.

[82] Maria Håkansson and Phoebe Sengers. 2013. Beyond Being Green: Simple Living Families and ICT. In Proc. CHI 2013.

[83] Christo Sims. 2017. Disruptive Fixation. School Reform and the Pitfalls of Techno-Idealism. Princeton, NJ: Princeton University Press.

[84] Noopur Raval and Paul Dourish 2016. Standing Out from the Crowd: Emotional Work, Body Work, and Temporal Work in Ridesharing. Proc. ACM Conf. Computer-Supported Cooperative Work CSCW 2016

[85] Jennifer Rode. 2011. A theoretical agenda for feminist HCI. Interacting with Computers, Vol. 23, Issue 5, 393-400.

[86] Daniela Rosner. Forthcoming. Critical Fabulations. MIT Press.

[87] Johan Söderberg and Alessandro Delfanti. 2015. Hacking Hacked! The Life Cycles of Digital Innovation. Science, Technology, and Human Values, Vol. 40 (5), 793-798.

[88] Stephanie Steinhardt, Amanda Menking, Ingrid Erickson, Andrea Marshall, Asta Zelenkauskaite, and Jennifer Rode. (2015). Feminism and feminist approaches in social computing. CSCW2015.

[89] Marilyn Strathern. 1991. Partial Connections. Lanham: Rowman and Littlefield. 
[90] Marilyn Strathern. 1992. Parts and wholes: Refiguring relationships in a post-plural world. In A. Kuper (ed.) Coceptualising Society. London: Routledge.

[91] Alex Taylor. 2011. Out there. In Proceedings of the SIGVHI Conference on Human Factors in Computing Systems (CHI 2011), 685-694.

[92] Tiziana Terranova. 2000. Free Labor. Producing Culture of the Digital Economy. Social Text 63 (Volume 18, Number 2).

[93] Kentaro Toyama. 2015. Geek Heresy. Rescuing Social Change from the Cult of Technology. PublicAffairs.

[94] Anna Tsing. 2015. The Mushroom at the End of the World. On the Possibility of Life in Capitalist Ruins. Princeton, NJ: Princeton University Press.

[95] Anna Tsing. 2005. Friction: An ethnography of global connection. Princeton University Press.

[96] Fred Turner. 2006. From Counterculture to Cyberculture. Stewart Brand, the Whole Earth Catalogue, and the Rise of Digital Utopianism. University of Chicago Press.

[97] Judy Wajcman. 2015. Pressed for Time. The Acceleration of Life in Digital Capitalism. University of Chicago Press.

[98] Frank Webster. 2006. Theories of the Information Society. Routledge.

Received April 2018; revised July 2018; accepted September 2018. 